\title{
Relation between energy metabolism, glycolysis, noradrenaline release and duration of ischemia
}

\author{
Anna Cargnoni, Claudio Ceconi, Salvatore Curello, Massimo Benigno, \\ Jan Willem de Jong ${ }^{1}$ and Roberto Ferrari ${ }^{2}$ \\ Fondazione Clinica del Lavoro, Centro di Fisiopatologia Cardiovascolare 'Salvatore Maugeri, 'Gussago, Brescia, Italy; \\ 'Thoraxcentre, Erasmus University Rotterdam, The Netherlands; ${ }^{2}$ Cattedra di Cardiologia, Universita' degli Studi di \\ Brescia, Brescia, Italy
}

\begin{abstract}
We studied the effect of 12-36 min of global ischemia followed by $36 \mathrm{~min}$ of reperfusion in Langendorff perfused rabbit hearts $(n=26)$. Metabolism was determined in terms of peak and total release of purines (adenosine, inosine, hypoxanthine), lactate and noradrenaline during reperfusion; and myocardial content of nucleotides (ATP, ADP, AMP), glycogen and noradrenaline at the end of reperfusion. An inverse relationship $(r=-0.79)$ existed between duration of ischemia and developed pressure post-ischemia. Early during reperfusion, after $12 \mathrm{~min}$ of ischemia, the purine concentration (peak release) increased $100 \times(\mathrm{p}$ $<0.01)$, that of lactate and noradrenaline $10 \times(\mathrm{p}<0.05)$. Total purine release rose with progression of the ischemic period $(30 \times$ after 36 min of ischemia; $p<0.01)$, concomitant with a reduction in nucleotide content. Lactate release was independent from the duration of ischemia, although glycogen had declined by $30 \%(\mathrm{p}<0.01)$ after $36 \mathrm{~min}$ of ischemia. The acid insoluble glycogen fraction, which presumably contains proglycogen, increased substantially during short-term ischemia. Peak noradrenaline increased $100 \times$ and $200 \times(\mathrm{p}<0.05)$ after 24 and $36 \mathrm{~min}$ of ischemia, respectively. Total noradrenaline release due to various periods of ischemia mirrored its peak release. Function recovery was inversely related to total purine and noradrenaline efflux (both $\mathrm{r}=-0.81$ ); it correlated with tissue nucleotide content $(\mathrm{r}=0.84)$. In conclusion, larger amounts of noradrenaline are released only after a substantial drop in myocardial ATP. During severe ischemia ATP consumption more than limited ATP production by anaerobic glycolysis, is a key factor affecting recovery on subsequent reperfusion. In contrast to lactate efflux, purine and noradrenaline release are useful markers of ischemic and reperfusion damage. (Mol Cell Biochem 160/161: 187194, 1996)
\end{abstract}

Key words: ATP breakdown. catecholamine, glycogen, ischemia

\section{Introduction}

Many critical factors are involved in the onset of severe myocardial ischemic damage. The most important are: (1) loss of tissue adenine nucleotide with consequent failure to restore energy metabolism with reperfusion [1-6]; (2) accumulation of toxic metabolites [7-9]; (3) calcium overload [10]; (4) release of noradrenaline [11-15]. Data about these metabolic alterations, however, derive from a combination of several individual studies employing a variety of different experimental preparations and ischemic protocols. In addition, the analytical techniques utilized for enzymatic determination of catecholamine and of adenine nucleotide often are of low sensitivity $[4,8,12,16,17]$.

There is therefore the need of systematic data analyzing in details the temporal sequences of the metabolic alterations which occur as ischemia progresses in the light of finding out the more suitable index of ischemic and reperfusion damage.

Isolated perfused heart preparation was selected for the present study because it allows the control of many variables that in vivo influence the severity of ischemic damage such as: myocardial perfusion, work load, substrate availability, neurohumoral factors. 


\section{Materials and methods}

\section{Heart perfusion}

Male New Zealand white rabbits $(2.0-2.3 \mathrm{~kg})$, maintained on a standard diet, were used. They were treated in conformity with the guiding principles of the American Physiological Society. The animals were stunned by a blow on the head; the hearts were quickly removed and perfused as previously described [18]. The perfusion solution was heated to $37^{\circ} \mathrm{C}$, bubbled with $95 \% \mathrm{O}_{2}$ and $5 \% \mathrm{CO}_{2}$ and transported at ate of $22 \mathrm{ml} / \mathrm{min}$ to the aortic cannula with a Gilson Minipuls 2 rotary pump. The hearts were jacketed $\left(40-44^{\circ} \mathrm{C}\right)$ to provide a constant myocardial temperature of $37^{\circ} \mathrm{C}$, independent of coronary flow, checked by an Ellab thermometric probe (model CTD 85) in the pulmonary artery. They were paced using suprathreshold rectangular pulses at $0.1 \mathrm{~ms}$ duration at a rate of 180 beats $/ \mathrm{min}$.

After a 30-min period of aerobic equilibration $(22 \mathrm{ml} / \mathrm{min})$, the hearts were randomly divided into four groups: Control, these hearts $(n=7)$ were aerobically perfused for a further period of $60 \mathrm{~min}$ (no ischemia); the other hearts were made ischemic by stopping the coronary flow for: (A) $12 \mathrm{~min}$ ( $\mathrm{n}=$ 7); (B) $24 \min (n=6)$; (C) $36 \min (n=6)$. At the end of ischemia, coronary flow was reestablished and all ischemic hearts were reperfused for $36 \mathrm{~min}$. Left ventricular pressure was determined from a fluid-filled balloon inserted into the ventricular cavity as previously described [18].

\section{Biochemical assays}

Analysis of coronary effluent

Coronary effluent fractions were collected in cooled vials $\left(0^{\circ} \mathrm{C}\right)$ at regular intervals during the entire period of reperfusion for purine, catecholamine and lactate determinations. Two $\mathrm{ml}$ of perfusate were added to $30 \mu 110 \mathrm{mM} \mathrm{Na}_{2} \mathrm{~S}_{2} \mathrm{O}_{5}$ for catecholamine assay. Another aliquot $(0.5 \mathrm{ml})$ was added to $1.0 \mathrm{ml} \mathrm{HClO}_{4}(6 \%)$ for the assay of lactate. Treated and untreated samples were stored at $-80^{\circ} \mathrm{C}$. Purines were determined with our reverse-phase high-pressure liquid chromatography (HPLC) method with detection at $254 \mathrm{~nm}[19,20]$. Noradrenaline was determined by reverse-phase HPLC with electrochemical detection on perfusate extracted with $\mathrm{Al}_{2} \mathrm{O}_{3}$ as previously described by us [21]. L-lactate was enzymatically determined by the method of Noll [22].

\section{Tissue determinations}

At the end of the experiments, the hearts were clamped with precooled Wollenberger tongs and stored in liquid nitrogen. The frozen tissue was homogenized with $\mathrm{HClO}_{4}$. The mixture was thawed and centrifuged; an aliquot of the supernatant fraction was neutralized with $\mathrm{KOH}$, and analyzed for nucleotide and catecholamine content. Nucleotides were determined by HPLC using the method of Harmsen et al. [23]. After $\mathrm{Al}_{2} \mathrm{O}_{3}$ extraction, noradrenaline was assayed as described above. Another aliquot was neutralized with $\mathrm{NaOH}$, and analyzed enzymatically for glycogen content [24, 25], using rabbit-liver glycogen as the standard.

In the acid precipitate, protein and glycogen were assayed. Protein was measured according to Bradford [26] using bovine serum albumine as the standard. A factor of $70 \mathrm{mg}$ protein/g wet weight was used to express release data, based on heart weight, per gram protein. Glycogen was determined as described before $[24,25]$.

\section{Statistics}

Data are reported as mean \pm S.E.M. A one-way analysis of variance was first carried out to test for any differences between all groups. If a difference was established, each of the groups was compared with the control group (aerobic control), using the unpaired $t$-test with Bonferroni correction. $\mathrm{p}<0.05$ was considered significant.

\section{Results}

\section{Mechanical changes}

During 60 min of control aerobic perfusion, mechanical function was well maintained since developed pressure declined only by $15 \%$ (n.s.). The recovered pressures, measured at the end of reperfusion after different ischemic periods are depicted in Fig. 1. Compared with the control group, there was a complete recovery of developed pressure in group $\mathrm{A}$, while, with prolongation of ischemia, it significantly decreased in groups $\mathrm{B}$ and $\mathrm{C}$ (to $66 \%$ and $38 \%$ of control, respectively; $\mathrm{p}<0.01$, see Fig. 1). There was an inverse relationship $(y=61.69-1.04 \times$; $\mathrm{r}=-0.79, \mathrm{p}<0.001)$ between the duration of ischemic period and the recovered pressure during reperfusion.

Diastolic pressure in the control hearts remained $0 \mathrm{mmHg}$ during the whole time of perfusion. The same was true for the hearts in group A. However, in groups B and C it rose to $24 \pm 11$ and $44 \pm 14 \mathrm{mmHg}$, respectively ( $p<0.001$ vs control, at the end of reperfusion) (Fig.1).

\section{Metabolite release}

When the hearts were perfused under aerobic conditions, small amounts of purine (adenosine, inosine and hypoxanthine), noradrenaline and lactate were present in coronary 


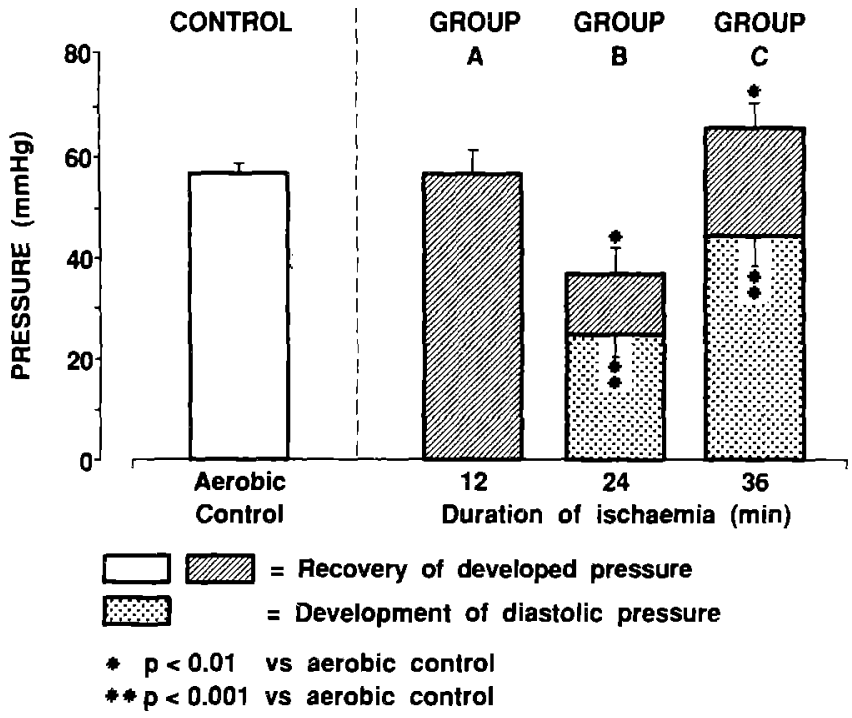

Fig. 1. Recovery of developed pressure and development of diastolic pressure after various periods of ischemia: decline in mechanical recovery and increment in diastolic tension are only evident after prolonged ischemia. For the non-ischemic controls (aerobic perfusion), the 60 min perfusion values were used. Mean values \pm S.E.M. $(n=6-7)$ are depicted. Pre-intervention left ventricular systolic pressure was $63.1 \pm 2.5 \mathrm{mmHg}$ and diastolic pressure was $0 \mathrm{mmHg}(\mathrm{n}=26)$.

effluent. Peak release of these metabolites was observed during the first minute of reperfusion (groups A, B and C, Fig. 2). Purine release, which was very low in control hearts $(0.044 \pm 0.004 \mu \mathrm{mol} / \mathrm{min} / \mathrm{g}$ protein $)$, became 100 -fold higher after 12 min of ischemia (group $A ; p<0.01$ ). If the ischemic period was prolonged from 12 to $24 \mathrm{~min}$ (group B) it increased and it doubled after 36 min of ischemia (group C, Fig. $2 \mathrm{~A}$ ). The peak releases of individual purines are shown in Table 1. Inosine represented the major component of total purine released in the aerobic period $(42 \%)$. After various ischemic periods (groups A, B and C), release of all purines increased. In particular, during reperfusion, inosine rose to $63 \%$ in group $\mathrm{C}$, at the expense of adenosine.

Peak noradrenaline release (Fig. $2 \mathrm{~B}$ ) rose 10 fold in group $A(p<0.05$ vs Control) and by an extra two orders of magnitude in groups $B$ and $C$. Peak lactate release reached already a plateau in group A ( $p<0.01$ vs Control, see Fig. 2 C).

Noradrenaline and lactate release declined to baseline in a few minutes ( 4 min for group B) whereas purine release persisted substantially longer (7-8 min for group B; Fig. 3).

Figure 4 shows the total release of the compounds determined in perfusate collected during $36 \mathrm{~min}$ of reperfusion. The behaviour observed for purines was quite similar to that described for their peak release (compare Figs. 2A and 4A). Total noradrenaline release in group $A$ was not different from that in control (Fig. 4B), whereas peak release in group A exceeded that in control 10-fold (Fig. 2B). No increment in total lactate release was observed after ischemia in groups $\mathrm{A}$, $\mathrm{B}$ and $\mathrm{C}$; all values were comparable to those obtained for

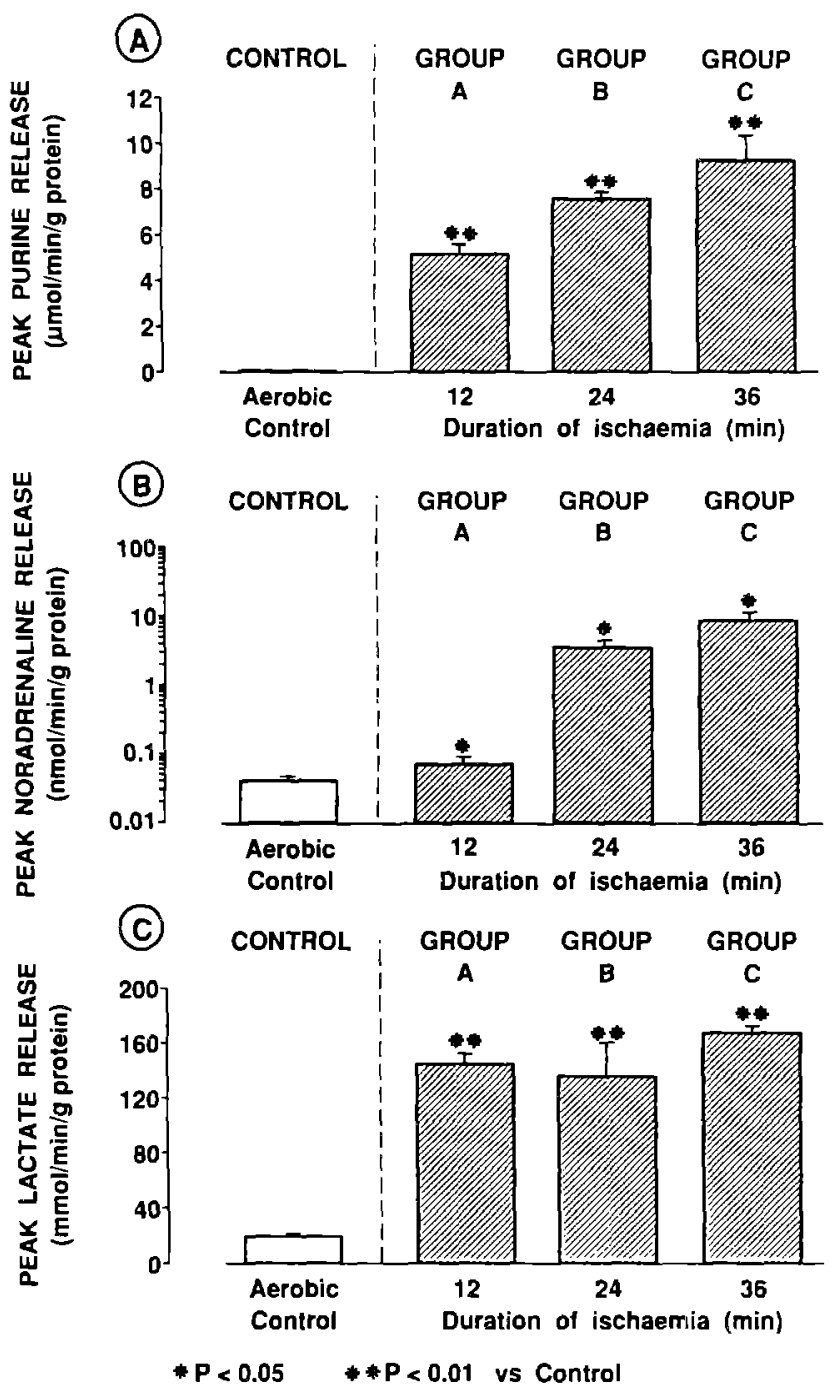

Fig. 2. Differences in peak release pattern of purines, noradrenaline and lactate after various periods of ischemia. Purines comprise adenosine, inosine and hypoxanthine. Please, note that the catecholamine data are given on a logarithmic scale. For other details, see legend to Fig. 1.

aerobic control perfusion (Fig. 4C), contrasting the behaviour of peak lactate release (Fig. 2C).

\section{Tissue changes}

The myocardial content of nucleotides (sum of ATP, ADP, and AMP), noradrenaline and glycogen is shown in Fig. 5. In groups $\mathrm{A}, \mathrm{B}$ and $\mathrm{C}$, total nucleotide content decreased ( $\mathrm{p}$ $<0.01$ ) compared with aerobic control (to $76 \%, 43 \%$ and $21 \%$, respectively, see Fig. $5 \mathrm{~A}$ ). The ATP, ADP and AMP levels are specified in Table 1 . There was a significant decline in ATP and ADP levels, proportional with the duration of the ischemic period. In contrast, AMP content decreased in group $A(p<0.05)$, and increased in groups B $(p<0.01)$ and $C$ (n.s.). 
Table 1. Purine release as well as nucleotide content after various periods of ischemia

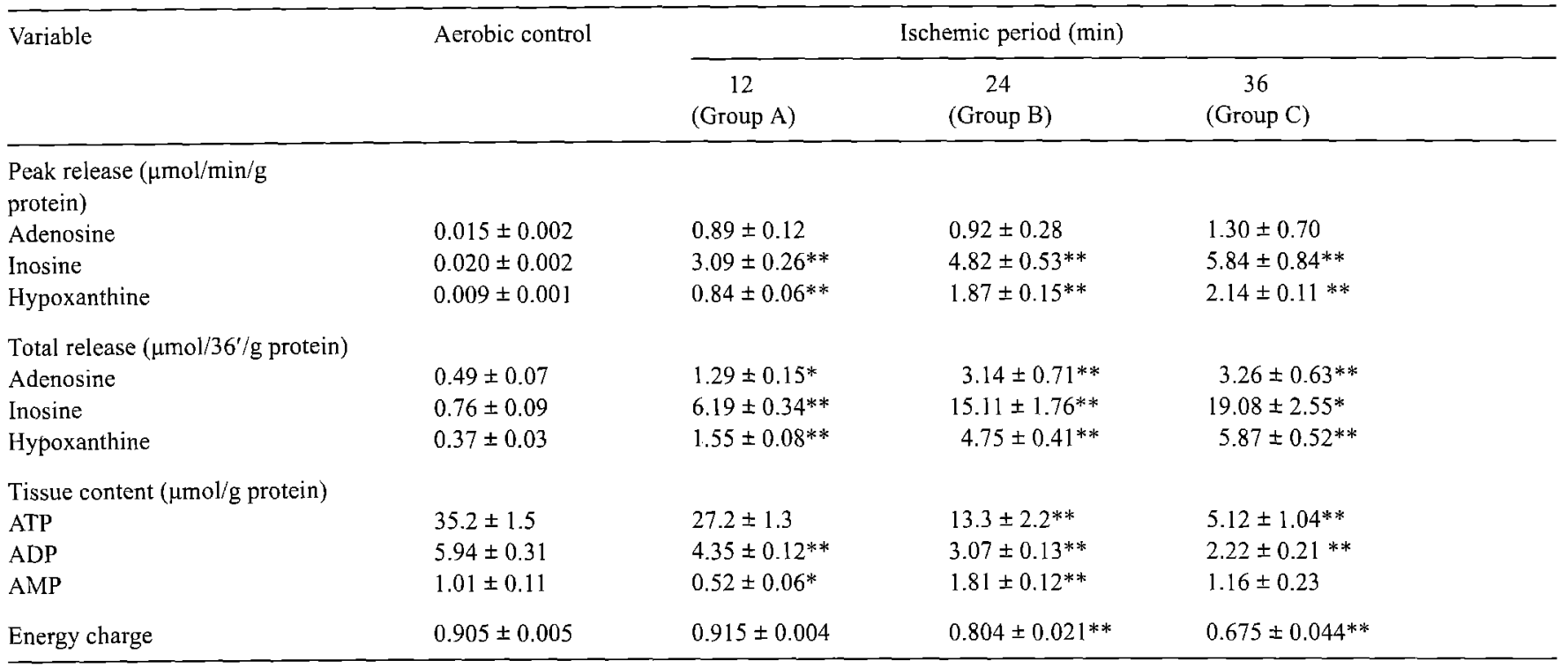

The values pertain to the 36-min reperfusion period, either early (peak release), over the whole period (total release), or to the end (myocardial content). The data show major ATP breakdown after the longer periods of ischemia. Energy charge is $[($ ATP $)+0.5($ ADP $)] /[($ ATP $)+($ ADP $)+($ AMP $)]$. Mean \pm S.E.M.; $n=$ $5-7 .{ }^{*} p<0.05, * * p<0.01$ vs control values

Besides myocardial nucleotide content, the phosphocreatine ( $\mathrm{PCr}$ ) tissue level was determined. In the control group, it amounted to $56.3 \pm 3.4 \mu \mathrm{mol} / \mathrm{g}$ protein at the end of experiment. No significant differences were observed due to ischemia/reperfusion.

Energy-charge data are useful to complete the view on myocardial energetic status in the reperfused hearts after various ischemic periods. The aerobic control value was $0.905 \pm 0.005$. Only in groups B and C energy charge decreased, to $88 \%$ and $75 \%$ with respect to control $(\mathrm{p}<0.01$, Table 1).

Panels B and C of Fig. 5 depict the noradrenaline and glycogen content. They show a decrease with the prolongation of the ischemic period from $12 \mathrm{~min}$ to 24 and $36 \mathrm{~min}$. The decrements in noradrenaline content were not statistically significant. Total glycogen decreased to $49 \%$ and $30 \%$ in groups B and C, respectively ( $p<0.001$ vs Control, Fig . 5C). Acid-insoluble glycogen increased from $7.3 \pm 0.4 \mathrm{mg} / \mathrm{g}$ protein in the control group to $17.1 \pm 1.6$ (group $\mathrm{A}, \mathrm{p}<0.001$ ), $12.3 \pm 1.9$ (group B, p < 0.05) and $7.7 \pm 1.3 \mathrm{mg} / \mathrm{g}$ protein (group C, n.s.)

\section{Correlation between function and metabolism}

The linear correlations between the recovery of developed pressure upon reperfusion and metabolite release (peak and total) as well as tissue content are reported in Table 2. A linear inverse and significant relationship existed between recovery of function and peak release of purines, noradrenaline and lactate, although in the last case, the correlation coefficient is low. The myocardial nucleotide and glycogen contents correlated strongly with developed pressure. Total lactate release and noradrenaline tissue content exhibited no linear relation with recovered mechanical function.

\section{Discussion}

\section{Energy metabolism}

We observed, in line with literature [6, 27-29], that reperfusion was unable to restore basal levels of cardiac adenine nucleotide content (Fig. 5A). This is especially true for ATP stores (see Table 1). In contrast to ATP, phosphocreatine was resynthetized during reperfusion. The finding of a declined AMP content in the hearts reperfused after 12 min of ischemia could be explained with the increased AMP dephosphorylation which occurs in anoxic and ischemic conditions. On the other hand, more severe ischemia causes large ATP catabolism with a probable congestion of the breakdown pattern and consequent AMP accumulation. More specifically, this accumulation could be due to increased cytosolic Pi which inhibits the activity of 5'-nucleotidase, the enzyme responsible for cardiac adenosine production [30].

Our data reveal that the lacking recovery in tissue adenine nucleotides, compared with aerobic levels, was balanced with purines lost during the reperfusion period (Table 1). This indicates that a portion of ATP, consumed during ischemia, 

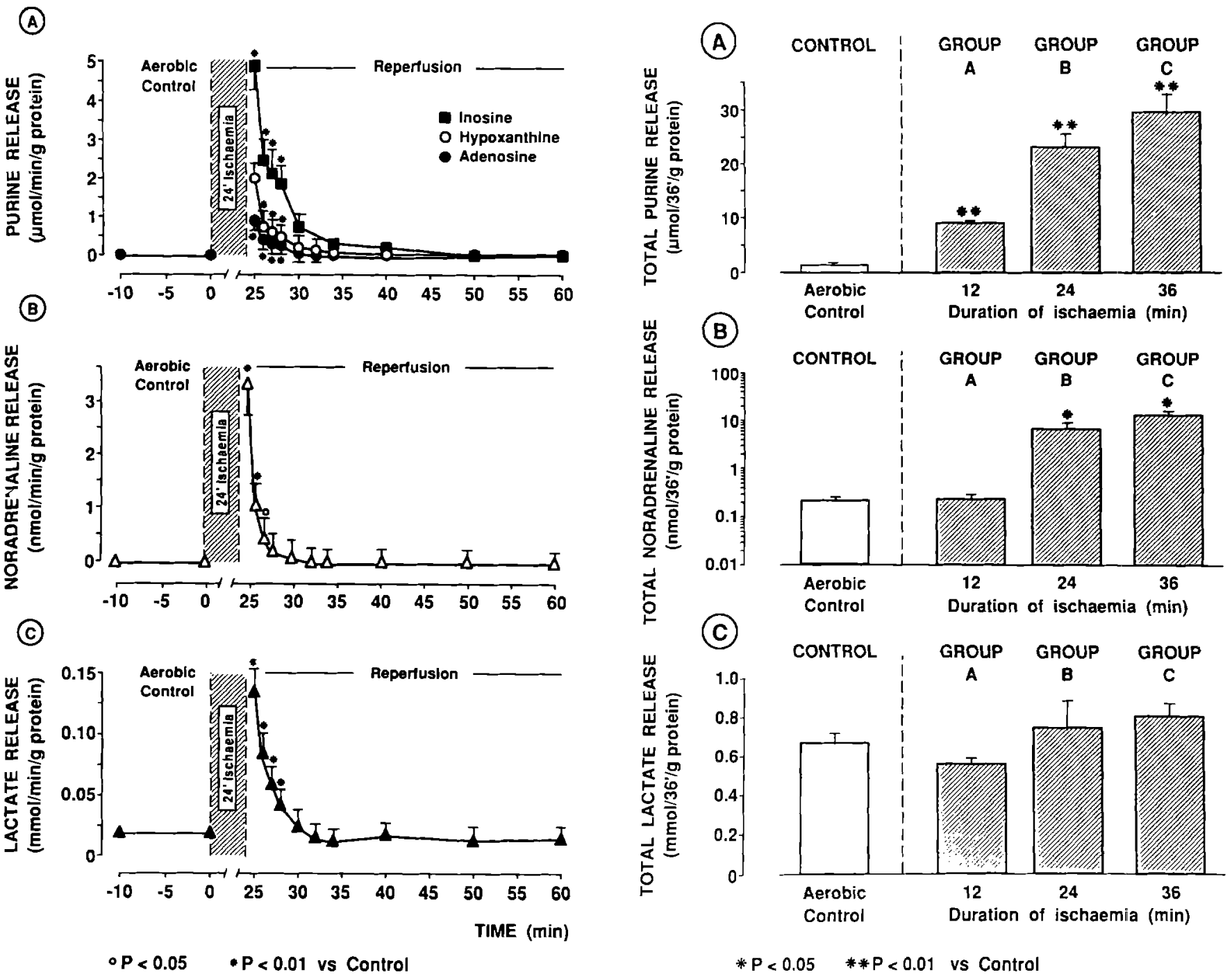

Fig. 3. Time course of metabolite release after $24 \mathrm{~min}$ of ischemia. The efflux of noradrenaline and lactate is already back to baseline in $4 \mathrm{~min}$, when purine release is still elevated. For other details, see legend to Fig. 1.

was not only degradated to ADP and AMP, but catabolized to adenosine, inosine and hypoxanthine which were immediately released from myocytes. Further degradation of hypoxanthine does not take place in rabbit heart [31].

After exhaustive ATP depletion during total ischemia [32], ATP levels can be partly restored during reperfusion from ADP by oxidative phosphorylation. But ATP resynthesis by the purine salvage pathway is too slow to play an important role in a relatively brief reperfusion period $[6,28,29]$. These data suggest that ATP degradation to purines during ischemia could slow high-energy phosphate restoration during reperfusion with delayed mechanical and metabolic cardiac recovery (stunned myocardium; ref. [27]). Our findings also emphasize the specificity of purine release to characterize the occurrence of myocardial ischemic conditions [33], where lactate release seems to be inadequate as a marker (Figs. 2 and 4 ).

Fig. 4. Differences in total release pattern of purines, noradrenaline and lactate after various periods of ischemia. Depicted are the amounts released during $36 \mathrm{~min}$ of reperfusion. Purines are released in proportion with duration of ischemia. Major noradrenaline release takes place only after the longer periods of ischemia, but no-flow does not affect total lactate release. For other details, see legends to Figs. 1 and 2.

\section{Noradrenaline release and tissue content}

The study of noradrenaline release rate is of relevance in oxygen deprivation conditions as already evidenced by the pionieristic work of Wollenberger A. et al. [34]. We found a large noradrenaline release at the first minute of reperfusion (peak release) after 12, 24 or $36 \mathrm{~min}$ of ischemia (Figs. 2B and 3B). This noradrenaline efflux represents washout of the neurotransmitter accumulated within the extracellular space during the ischemic period $[14,35,36]$. We observed also an increment of noradrenaline release during the whole reperfusion period (total release), after 24 and $36 \mathrm{~min}$ of 

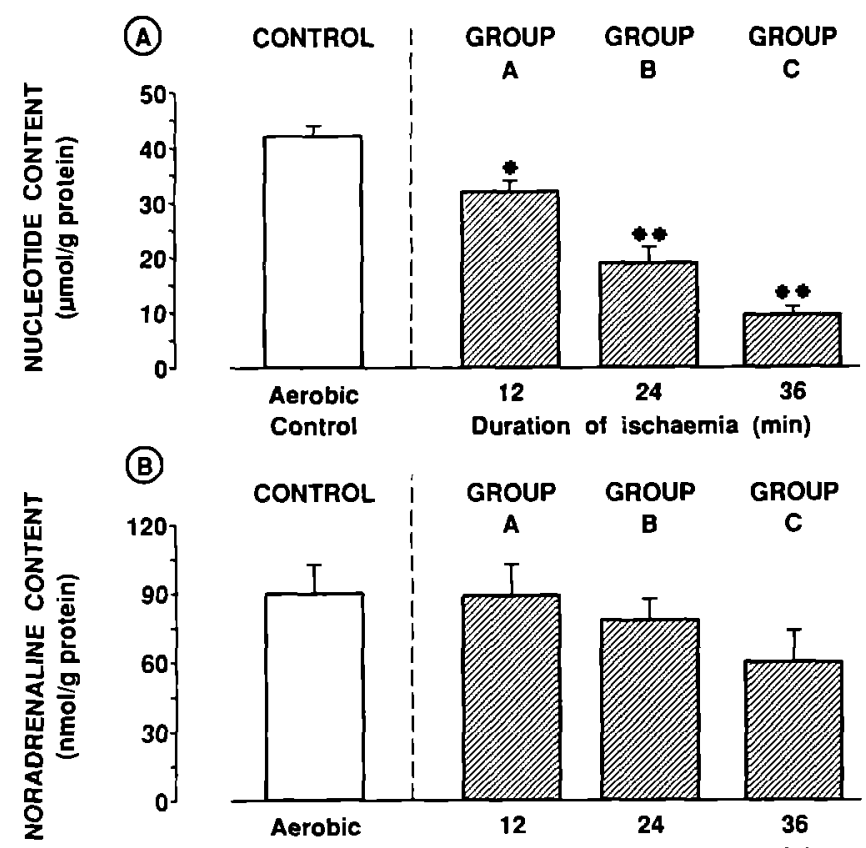

(B) CONTROL
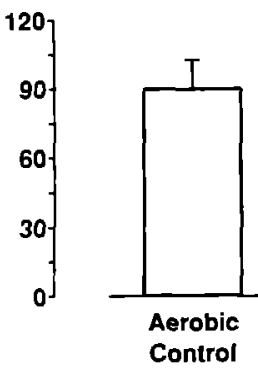

$$
\text { i }
$$

GROU
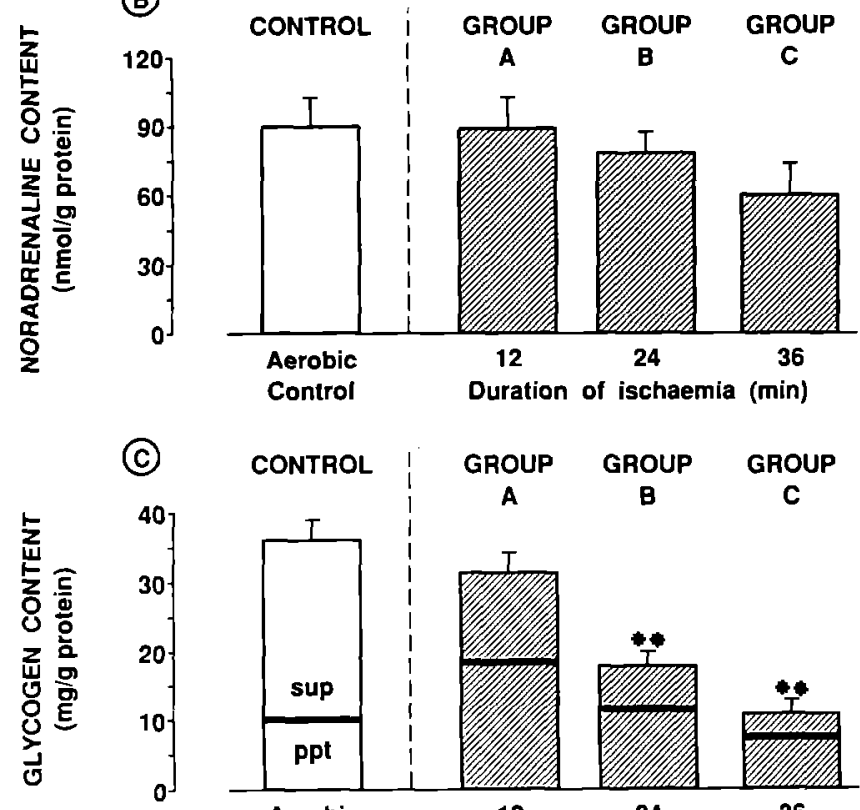

(C) CONTROL

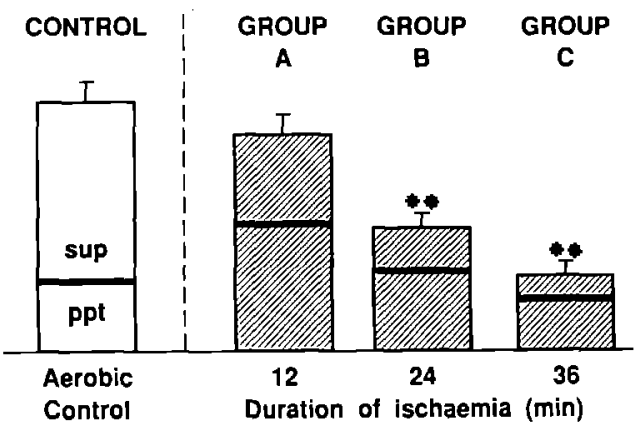

$* P<0.01 * P<0.001$ vs Control

Fig. 5. Decline in tissue nucleotide, noradrenaline, and glycogen content after various periods of ischemia. Adenine nucleotides comprise ATP, ADP and AMP. Glycogen found in the acid-soluble (sup) and acid-insoluble (ppt) fractions is given in the upper and lower portions of the bars, respectively. The ratio sup/ppt in the post-ischemic groups differed from Control $(p<0.001)$. The data show substantial nucleotide and glycogen (acid-soluble) breakdown with increased duration of ischemia, with minor changes in noradrenaline content. The shorter period of ischemia induces an increase in the acid-insoluble glycogen fraction, which presumably comprises proglycogen. For other details, see legend to Fig. 1. ischemia (Fig. 4B), and a balanced, progressive, but not significant, decline in myocardial noradrenaline content (Fig. $5 \mathrm{~B})$. On the other hand, it should be recalled that noradrenaline released during reperfusion represents only a small portion, from $0.1-14 \%$, of the basal tissue content.

Based on the positive relationship between total noradrenaline release and total purine release $(\mathrm{r}=0.80, \mathrm{p}<0.001)$ and on the inverse correlation with ATP myocardial levels $(\mathrm{r}=-0.75, \mathrm{p}<0.001)$ and glycogen content $(\mathrm{r}=-0.71, \mathrm{p}<$ $0.001)$, we propose the following influence of endogenous noradrenaline on energetic and carbohydrate metabolism during myocardial ischemia. Released noradrenaline stimulates glycogenolysis by cyclic-AMP formation and activation of phosphorylases, as earlier suggested [13, 37]. Metz and Bernauer [16] hypothesized that noradrenaline release is not essential for the activation of anaerobic glycogenolysis, but is important for stimulating anaerobic glycolysis [14]. However, these authors found no evidence for an alternative regulating mechanism during ischemia [16].

Our data also suggest that cardiac noradrenaline, e.g. by activation of a phosphatase such as mitochondrial ATPase, could affect breakdown of ATP stores, exacerbating the ischemic consumption of high-energy phosphates. However, little is known about the effect of noradrenaline on metabolism during myocardial ischemia, in contrast to the great number of studies on its arrhythmogenic and inotropic effects upon reperfusion [11, 13-15). In the light of these novel data and observation, the metabolic role of noradrenaline released during ischemia deserves more attention. As a marker of ischemia, it is perhaps only useful after longer periods of ischemia (cf. Figs. 2B and 4B).

\section{Glycolytic metabolism}

The glycolytic pathway is profoundly changed by ischemia. In the early phase of ischemia, glycogenolysis is stimulated by local catecholamine release [13]; phosphofructokinase is activated by an increase in ADP, AMP and Pi levels and a contemporary reduction in ATP content [37]. As a result, anaerobic glycolysis is accelerated, with ATP production and lactate accumulation [5]. We have studied alterations in gly-

Table 2. Correlation between function recovery and metabolic variables after various periods of ischemia

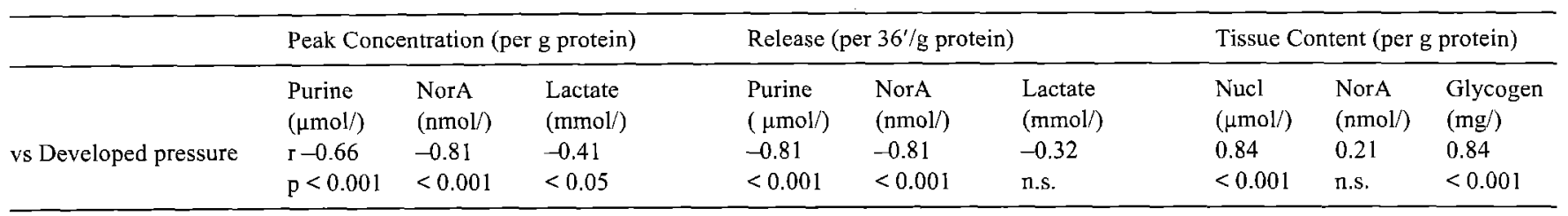

Calculated are the correlation coefficients and their p-values for developed pressure vs peak and total release of metabolites, and vs tissue compounds. Function data, obtained at the end of normoxic control perfusion and after 36 min of reperfusion were used. Mean \pm S.E.M. $(n=24-26)$. NorA $=$ noradrenaline, Nucl $=$ adenine nucleotides 
colytic metabolism, determining myocardial glycogen content and lactate release upon reperfusion. In agreement with the literature [17], our results show that, after reperfusion, the glycogen content was reduced proportionally with the duration of ischemia. Furthermore, myocardial glycogen levels were closely correlated with the recovery of developed pressure after different ischemic periods (Table 2). We expected lactate release during reperfusion to be correlated with glycogen consumption. During 36 min of reperfusion, we observed that all reperfused hearts maintained a total lactate release similar to control hearts (Fig. 4C). However, at the first minute of reperfusion, all treated groups showed a high lactate release, compared with aerobic release. These peak releases were independent of the period of ischemia (12-36 min, Fig. 2C). Increased peak release is in apparent contrast with correspondent unchanged total release (cf. Fig. $2 \mathrm{C}$ and 4C), but is explained by lower-than-baseline lactate release after the early minutes of reperfusion (Fig. 3C).

We want to underline that lactate washout is independent from the duration of ischemia. Possible mechanisms include either a saturable lactate export from the myocardial cells or an inhibition of anaerobic glycolysis, without a stop in glycogenolysis. The first hypothesis is unproved because lactate accumulating in tissue was released approximately in proportion to the tissue concentration [38]. The latter hypothesis is supported by several studies: when ischemia is prolonged, glyceraldehyde-3-phosphate dehydrogenase and phosphofructokinase are inhibited by excess NADH, acidosis and lactate accumulation [39-42]. Therefore, lactate production stops while other glycolytic products accumulate in myocytes, such as glucose-1-phosphate and glucose-6-phosphate $[5,41,43$, 44]. For this reason lactate as a quantitative marker for myocardial ischemia is unacceptable (see also Figs. $2 \mathrm{C}$ and $4 \mathrm{C}$ ). Apstein et al. [45] already pointed at the limitations of lactate production as an index of myocardial ischemia.

A novel observation is the substantial increase in acid-insoluble glycogen due to 12 or $24 \mathrm{~min}$ of ischemia, followed by reperfusion. This fraction presumably comprises of proglycogen, a low-molecular-weight form of glycogen with the protein glycogenin attached to it [46]. Glycogenin primes glycogen biogenesis [47]. Further investigations have to substantiate that proglycogenin, described for skeletal muscle [46], does indeed occur in myocardial tissue, where it may be affected by ischemia/reperfusion.

\section{Conclusion}

Our data demonstrate that: (1) impaired restoration of myocardial function during reperfusion is correlated with a large loss of purines and consequent delay to reestablish adequate myocardial energy metabolism; (2) ATP production by anaerobic glycolysis is independent from the duration of ischemia; (3) cardiac noradrenaline release is possibly involved in aggravating energy waste during ischemia. These findings suggest that manipulations which increase energy saving during ischemia [5] or that inhibit purine release, with accelerated repletion of ATP stores on reperfusion [19, 29], are useful to improve mechanical function during postischemic reperfusion. In contrast to lactate release, purine and possibly noradrenaline release are useful markers of ischemic damage.

\section{Acknowledgements}

This work has been supported by the National Research Council (C.N.R.) target project 'Prevention and control of disease factors' \# 91.00156PS41. We thank Miss Roberta Ardesi, Miss Patrizia Martina, Miss Selma Nieukoop and Miss Michela Palmieri for their expert technical assistance, and Miss Roberta Bonetti for secretarial help.

\section{References}

1. Asimakis GK, Sandhu GS, Conti VR, Sordahl LA, Zwischenberger JB: Intermittent ischemia produces a cumulative depletion of mitochondrial adenine nucleotides in the isolated perfused rat heart. Circ Res 66: 302-310, 1990

2. Clarke K, O'Connor AJ, Willis RJ: Temporal relation between energy metabolism and myocardial function during ischemia and reperfusion. Am J Physiol 253: H412-H42 I, 1987

3. De Scheerder IK, Maas AAM, Nieukoop AS, Van der Meer P, Huizer T, Roelandt JRTC, De Jong JW: Cardiac ATP breakdown and mechanical function during recurrent periods of anoxia. Cardioscience 3: 189-195, 1987

4. Jennings RB, Reimer KA, Hill ML, Mayer SE: Total ischemia in dog hearts, in vitro. Circ Res 49: 892-900, 1981

5. Murry CE, Richard VJ, Reimer KA, Jennings RB: Ischemic preconditioning slows energy metabolism and delays ultrastructural damage during a sustained ischemic episode. Circ Res 66: 913-931, 1990

6. Reibel DK, Rovetto MJ: Myocardial adenosine salvage rates and restoration of ATP content following ischemia. Am J Physiol 237: H247H252, 1978

7. Katz AM, Messineo FC: Lipid membrane interactions and the pathogenesis of ischemic damage in the myocardium. Circ Res 48: 116,1981

8. Neely JR, Grotyohann LW: Role of glycolytic products in damage to ischemic myocardium. Circ Res 55: 816-824, 1984

9. Van der Vusse GJ, Stam H: Lipid and carbohydrate metabolism in the ischaemic heart. Basic Res Cardiol 82 (suppl 1): 149-153, 1987

10. Nayler WG: The role of calcium in the ischemic myocardium. Am J Pathol 102: 262-270, 1981

11. Carlsson L, Abrahamsson T, Almgre O, Svensson: Ischemia-induced release of noradrenaline and creatine kinase in the isolated, working rat heart. Acta Physiol Scand 130: 83-93, 1987

12. Dart AM, Riemersma RA, Schömig A, Ungar A: Metabolic requirements for release of endogenous noradrenaline during myocardial ischemia and anoxia. Br J Pharmacol 90: 43-50, 1987

13. Mayer SE, Williams BJ, Smith JM: Adrenergic mechanisms in glyco- 
gen metabolism. Ann NY Acad Sci 39: 682-702, 1967

14. Schömig A, Dart AM, Dietz R, Mayer E, Kübler W: Release of endogenous catecholamines in the ischemic myocardium of the rat. Part A: locally mediated release. Circ Res 55: 689-701, 1984

15. Schömig A, Fischer S, Kurz T, Richardt G, Schömig E: Nonexocytotic release of endogenous noradrenaline in the ischemic and anoxic rat heart: Mechanism and metabolic requirements. Circ Res 60: 194-205, 1987

16. Metz V, Bernauer N: The effect of reserpine and guanethidine on carbohydrate metabolism in ischaemic rat myocardium. Cardiovasc Res 23: 385-389, 1989

17. Taegtmeyer H, Roberts AFC, Raine AEG: Energy metabolism in reperfused heart muscle: Metabolic correlates to return of function. J Am Coll Cardiol 6: 864-870, 1985

18. Ferrari R, Ceconi C, Curello S, Guarnieri C, Caldarera CM, Albertini A, Visioli $O$ : Oxygen mediated myocardial damage during ischemia and reperfusion. Role of cellular defence against oxygen toxicity. J Mol Cell Cardiol 17: 937-945, 1985

19. De Jong JW, Harmsen E, De Tombe PP, Keijzer E: Nifedipine reduces adenine nucleotide breakdown in ischemic rat heart. Eur $\mathrm{J}$ Pharmacol 81: 89-96, 1987

20. Harmsen E, De Jong JW, Serruys PW: Hypoxanthine production by ischemic heart demonstrated by high pressure liquid chromatography of blood purine nucleosides and oxypurines. Clin Chim Acta 115: 7384,1987

21. Ceconi C, Condorelli E, Quinzanini M, Rodella A, Ferrari R, Harnis P: Noradrenaline, atrial nutriuretic peptide, bombesin and neurotensin in myocardium and blood of rats in congestive cardiac failure. Cardiovasc Res 23: 674-682, 1989

22. Noll F: L-(+)-Lactate. In: HU Bergmeyer (ed.) Methods of Enzymatic Analysis, Vol 6, 3rd ed., Verlag Chemie, Weinheim, 1984, pp 582588

23. Harmsen E, De Tombe PP, De Jong JW: Simultaneous determination of myocardial adenine nucleotides and creatine phosphate by high pressure liquid chromatography. J Chromatogr 230: 131-136, 1987

24. Bergmeyer HU, Bernt E: Glycogen-determination with glucose oxidase and peroxidase. In: HU Bergmeyer (ed.) Methods of Enzymatic Analysis, Vol 3, 2nd ed., Verlag Chemie, Weinheim, 1974, pp 12051215

25. Keppler D, Decker K: Glycogen-determination with amyloglucosidase. In: HU Bergmeyer (ed.) Methods of Enzymatic Analysis, Vol. 3, 2nd ed., Verlag Chemie, Weinheim, 1974, pp 1127-1131

26. Bradford MM: A rapid and sensitive method for the quantification of microgram quantities of protein utilizing the principle for protein binding. Anal Biochem 72: 248-254, 1978

27. Flameng $W$, Sukekiro $S$, Molihoff $T$, Van Belle $H$, Janssen P: A new concept of long-term donor heart preservation: Nucleotide transport inhibition. J Heart Lung Transplant 10 (suppl 6): 990-998, 1987

28. Harmsen E, De Tombe PP, De Jong JW, Achterberg PW: Enhanced ATP and GTP synthesis from hypoxanthine or inosine after myocardial ischemia. Am J Physiol 246: H37-H43, 1984)

29. Swain JL, Heines JJ, Sabrina RL, Holmes EW: Accelerated repletion of ATP and GTP pools in post-ischaemic canine myocardium using a precursor of purine de novo synthesis. Circ Res 51(1): 102-105, 1982

30. Itoh R, Oka J, Ozasa H: Regulation of rat heart cytosol 5'-nucleotidase by adenylute energy charge. Biochem J 235:847-851, 1984

31. De Jong JW, Van der Meer P, Nieukoop AS, Huizer T, Stroeve RJ, Bos E. Xanthine oxidoreductase activity in perfused hearts of various species, including humans: Circ Res 67: 770-773, 1987

32. Steenbergen C, Murphy E, Watts JA, London RE: Correlation between cytosolic free calcium, contracture, ATP and irreversible ischemic injury in perfused rat heart. Circ Res 66: 135-146, 1990

33. Remme WJ, De Jong JW, Verdouw PD: Effects of pacing-induced myocardial ischemia on hypoxanthine efflux from the human heart. Am J Cardiol 40: 55-62, 1977

34. Wollenberger A, Shahab L: Anoxia-induced release of noradrenaline from the isolated perfused heart. Nature 207 (992): 88-89, 1965

35. Abrahamsson T, Almgren O, Carlsson L: Wash-out of noradrenaline and its metabolites by calcium-free reperfusion after ischemia: Support for the concept of ischemia induced noradrenaline release. $\mathrm{Br} \mathrm{J}$ Pharmacol 81 (suppl 1): 22-24, 1984

36. Carlsson L, Abrahamsson T: Characterization of the inhibitory effect of some antidepressant drugs on the outward transport of norepinephrine in the ischemic myocardium. J Pharmacol Exp Ther 247: 715720,1988

37. Wollenberger A, Krause E: Metabolic control characteristics of the acutely ischemic myocardium. Am J Cardiol 22: 349-359, 1968

38. Makdessi SA, Andrieu JL, Chah QT, Tuduri AJ, Faucon G: Relationship between lactate arteriovenous gradient and tissue lactate content in subendocardial and subepicardial layers of the ischaemic in situ heart. Cardiovasc Res 16: 552-558, 1982

39. Gelet TR, Altschuld RA, Weissler AM: Effects of acidosis on the performance and metabolism of the anoxic heart. Circulation 39/40 (suppl. IV): $60-69,1987$

40. Kübler W, Spieckermann PG: Regulation of glycolysis in the ischemic and anoxic myocardium. J Mol Cell Cardiol $1: 351-377,1970$

41. Rovetto MJ, Lamberton WF, Neely JR: Mechanism of glycolytic inhibition in ischemic rat hearts. Circ Res 37: 742-751, 1975

42. Williamson JR, Schaffer S, Ford C, Safer B: Contribution of tissue acidosis to ischemic injury in the perfused rat heart. Circulation 53 (suppl 1): 3-14, 1976

43. Neely JR, Morgan HE: Relationship between carbohydrate and lipid metabolism and the energy balance of heart muscle. Annu Rev Physiol 36: $413-459,1974$

44. Opie LH: Effects of regional ischemia on metabolism of glucose and fatty acids: Relative rates of aerobic and anaerobic energy production during myocardial infarction and comparison with effects of anoxia. Circ Res 38: 52-74, 1976

45. Apstein CS, Gravino F, Hood JW Jr: Limitations of lactate production as an index of myocardial ischemia. Circulation 60: 877-888, 1979

46. Lomako J, Lomako WM, Whelan WJ: Proglycogen: A low-molecular weight form of muscle glycogen. FEBS Lett 279: 223-227, 1991

47. Smythe C, Cohen $P$ : The discovery of glycogenin and the priming mechanism for glycogen biogenesis. Eur J Biochem 200: 625-631, 1991 